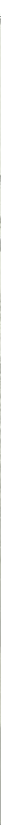

Bakgrunn: Overlevelse etter hjertestans blir redusert med 10-15 prosent for hvert minutt som går uten at hjerte-lunge-redning (HLR) blir iverksatt. Suksessfaktorene for overlevelse er tidlig igangsetting av HLR, og god kvalitet på utførelsen.

Hensikt: Hensikten med prosjektet var å måle kvaliteten på avansert HLR (AHLR) under simuleringstrening for å se om resultatene ville tilfredsstille de nasjonale retningslinjene fra 2005

Metode: Prospektiv observasjonsstudie under fullskala simulerings- trening. Data ble innhentet fra PC koplet til dukke, samt videoopptak. 48 sykepleiere og 16 leger tilknyttet en hjerteovervåkningsavdeling deltok i prosjektet.

Resultater: Gjennomsnittlig kompresjonsfrekvens var på 104, med en gjennomsnittlig dybde på $48 \mathrm{~mm}$. Det tok 82 sekunder (median) fra ventrikkelflimmer til første DC-støt når defibrillatoren sto utenfor rommet, og 25 sekunder (median) når defibrillatoren var inne på rommet. Total hands-off tid var på 25 prosent. Medikamenter ble gitt korrekt i de fleste av tilfellene (92 prosent), og det var høy grad av dobbeltkontroll (94 prosent). Det ble som oftest komprimert når defibrillatoren ble ladet (86 prosent), mens det ved 17 prosent. av tilfellene ble avlevert DC-støt uten å følge sikkerhetsrutinene. Når man ifølge retningslinjene kunne gi påfølgende DC-støt ble dette utført i omtrent halvparten tilfellene (54 prosent).

Konklusjon: Kvaliteten på utført AHLR tilfredsstiller de nasjonale retningslinjene fra 2005. Algoritmen blir fulgt i så godt som alle scenarioer, og den tekniske utførelsen er god. Resultatene tilsier ingen un $\varnothing$ dig hands-off tid.
Background: The survival rate after cardiac arrest decreases by $10-15 \%$ for each minute without cardiopulmonary resuscitation (CPR). Early introduction of CPR and good quality of performance are important predictors of survival.

Objectives: The objective of this project was to measure the quality of advanced CPR during simulation training, and to see if the results are in accordance with the Norwegian guidelines of 2005 .

Methods: Prospective observational study during full-scale simulation training. Data were collected from a computer connected to a manikin, in addition to video recordings 48 nurses and 16 physicians working at an intensive coronary care unit (ICCU) participated.

Results: Mean frequency of chest compressions was 104, with a mean depth of $48 \mathrm{~mm}$. Time from occurrence of ventricular fibrillation to delivered countershock was median 82 seconds and median 25 seconds when the defibrillator was located outside or inside the room, respectively. The total hands-off time was $25 \%$. Mostly, medications were given correctly (92\%) with a high degree of double control (94\%). Chest compression was continued during charging of the defibrillator in $86 \%$ of the charging intervals. In $17 \%$ of the episodes, countershocks were delivered without following the safety precautions. When consecutive countershocks could have been given according to guidelines, it was performed in half of the cases (54\%).

Conclusion: The quality of performed advanced CPR is in accordance with the Norwegian guidelines of 2005 . The algorithm was followed correctly in almost every scenario, and the technical performance was good. Current results indicate no unnecessary hands-off time.

Keywords: Quality, Simulation Training, Cardiopulmonary Resuscitation. 


\section{Kvaliteten på avansert hjerte- og lungeredning under simuleringstrening}

Forfattere: Mikael Næss, Trine-Lise Ellingsen, Siw Pedersen Trudvang og Anne Siri Rokvam

\section{NøKKELORD}

- Kvalitet

- Simuleringstrening

- Hjerte-og lungeredning

\section{INNLEDNING}

Hvert år rammes om lag 2500 mennesker av hjertestans i Norge (1). Sjansen for å overleve en hjertestans blir redusert med 10-15 prosent for hvert minutt som går uten at hjerte-lunge-redning (HLR) blir iverksatt. Suksessfaktorene for overlevelse er tidlig igangsetting av HLR, særlig innenfor de første 3-5 minuttene, og god kvalitet på utførelsen (2).

Tidligere studier har vist varierende kvalitet på HLR blant helsepersonell. I en norsk studie publisert i 2005 på 176 prehospitale hjertestanser ble det påvist at brystkompresjoner, i gjennomsnitt, ikke ble gitt i halvparten av tiden der pasienten var uten sirkulasjon. Når det ble justert for EKG-analyse og defibrillering var det fremdeles 38 prosent handsoff tid, og i tillegg var brystkompresjonene som ble gitt for svake (3). En studie fra Chicago, publisert samme år, på 76 in-hospitale hjertestanser viste at brystkom- presjonene hadde for lav frekvens i tillegg til at de var for grunne. Over 60 prosent ble hyperventilert og hands-off tiden var for lang. HLR ble ifølge studien utført av et veltrent sykehuspersonell (4). Etter innføring av nye retningslinjer i $2005(5 ; 6)$ viste en norsk studie fra 2009 signifikant reduksjon i hands-off tid, og signifikant bedring av brystkompresjons- og ventilasjonshastighet sammenliknet med perioden før modifiseringen av retningslinjene (7).

På Kardiologisk intensiv og overvåkning (KIO) ved Oslo universitetssykehus (OUS), Ullevål, var det i 2009, 35 pasienter som fikk hjertestans i avdelingen (8). Det vil si en hjertestans, i gjennomsnitt, hver tiende dag. Av disse overlevde 24 (68,5 prosent). For å kunne yte tilfredsstillende kvalitet ved akutte hendelser trener avdelingens leger og sykepleiere på avansert hjerte-lungeredning (AHLR) to ganger årlig.

Hensikten med prosjektet var å måle kvaliteten på AHLR under trening på simuleringssenteret for å se om resultatene ville tilfredsstille de nasjonale retningslinjene fra 2005. Avdelingen legger årlig ned ressurser i fagutvikling og kompetanseheving, og AHLR prioriteres høyt. Av den grunn var det interessant å få doku- mentert kvaliteten og eventuelt synliggjøre forbedringspotensialer, slik at fremtidig trening kan bli rettet mot dette.

\section{METODE}

Prosjektet ble gjennomført som en prospektiv observasjonsstudie i forbindelse med avdelingens

\section{Hva tilfører artikkelen}

Undersøkelsen av nivået på avansert hjerte- og lungeredning under simuleringstrening ved Oslo universitetssykehus, Ullevål, viser at dette tilfredsstiller nasjonale retningslinjer.

\section{Mer om forfatterne:}

Mikael Næss er intensivsykepleier med master i sykepleievitenskap. Han jobber som ledende spesialsykepleier ved kardiologisk intensiv og overvåkning (KIO), kardiologisk avdeling. Trine-Lise Ellingsen er intensivsykepleier, AHLR-kursleder og spesialsykepleier ved kardiologisk intensiv og overvåkning (KIO), kardiologisk avdeling. Siw Pedersen Trudvang er intensivsykepleier, AHLR-kursleder og ledende spesialsykepleier, kardiologisk intensiv og overvåkning (KIO). Anne Siri Rokvam er intensivsykepleier, simulerings- og hovedinstrukt $\varnothing r$ HLR ved utdanningssenteret. Alle er ansatt ved Oslo universitetssykehus HF, Ullevål. Kontakt: minsa uus.no. 
obligatoriske trening på simuleringssenteret (SIM). I løpet av åtte virkedager i oktober 2010 deltok daglig to leger og fire til seks sykepleiere. Det ble gjennomført tre fullskala scenarioer med tverrfaglige team på en avansert dukke som ga respons på behandlingen. Følgende er en kort beskrivelse av de ulike scenarioene:

1) 46 år gammel kvinne som er innlagt med synkope. Koronar angiografi viste åpne kransarterier. To minutter etter scenariostart får hun ventrikkelflimmer. Hun trenger to DC-støt (HLR i tre minutter mellom støtene) for å få tilbake sinusrytme. Er da sirkulatorisk stabil i cirka to minutter før hun på nytt får ventrikkelflimmer. To nye DC-støt gir henne sinusrytme og scenarioet avsluttes etter ytterligere to minutter.

2) 65 år gammel kvinne som er innlagt på grunn av STEMI i nedreveggen. Utført PCI på RCA. Er bradykard på angiolab og får Atropin. Etter ankomst til overvåkningen er hun kvalm, lett hypotensiv og sirkulatorisk støt og AHLR i 18 minutter. Blir intubert prehospitalt. Kjøres direkte til angiolab der det blir utført PCI med stent på LAD. Scenarioet starter når pasienten har ankommet overvåkningen. Ligger da på respirator. Over en periode på seks minutter blir han gradvis mer takykard og faller i blodtrykk. Får deretter ventrikkelflimmer som det kreves tre DC-støt (HLR i tre minutter mellom støtene) for å få tilbake i sinusrytme. Pasienten har reokklusjon og scenarioet avsluttes når det blir besluttet å transportere han til angiolab.

Teamet var sammensatt som i klinikken, og all behandling skulle bli utført som i praksis. Simuleringstrening er ikke rollespill og deltakerne er seg selv som fagpersoner. På de to første scenarioene deltok én lege og tre sykepleiere, mens det var to leger og fire sykepleiere på det siste. De som ikke deltok på et scenario satt på debrifingsrommet og fulgte med ved hjelp av kameraoverføring.

Data ble registrert i en PC som var koplet til trenings-

\section{Simuleringstrening er ikke rollespill og deltakerne er seg selv som fagpersoner.}

påvirket. Hun har sinusrytme som etter tre minutter går over til en AV-blokk grad 3 med frekvens på 30. AV-blokken varer i tre minutter for deretter å gå over til ventrikkelflimmer. Det kreves tre DC-støt (HLR i tre minutter mellom støtene) for å få tilbake AV-blokk grad 3 med frekvens 50 som gir tilfredsstillende sirkulasjon. Scenarioet avsluttes etter ytterligere 3 minutter.

3) 55 år gammel mann med hjertestans i hjemmet. Kona startet HLR før ambulansen kom. De ga til sammen tre DC- dukka. Dukka var av modellen ResusciAnne Simulator fra Laerdal og PC-programvaren var Laerdal PC Skillreporting System versjon 2.2.1. Her ble det registrert dybde og frekvens på brystkompresjonene, handsoff tid - det vil si tiden det ikke blir gitt brystkompresjoner etter bekreftet hjertestans, "leaning» - brystkompresjoner som ikke blir sluppet helt opp, og tid fra støt. Data ble videre behandlet i Microsoft Excel. Medianverdi ble brukt der tallmaterialet ventrikkelflimmer til første DC- hadde noen få ekstreme avvik.

Alle scenarioer ble spilt inn på video der deler ble vist i forbindelse med debrifingen. Dette er vanlig ved alle SIM-treninger og ikke designet for dette prosjektet. Filene ble beholdt i etterkant av prosjektleder for videre datainnsamling. Her ble det registrert om medikamenter ble gitt, og om de ble gitt til rett tid og med rett dose. "Closed loop» ble vurdert og brukt som mål på kommunikasjonen mellom teammedlemmene. Det vil si å få tydelig tilbakemelding fra de andre i teamet på at de har oppfattet informasjon som har blitt gitt. I forbindelse med dette prosjektet ble «closed loop» vurdert i forbindelse med administrasjon av medikamenter.

Sikkerhet ved defibrillering ble også registrert. Her skulle følgende to faktorer være til stede for at den kunne betegnes som tilfredsstillende; tydelig verbal påminnelse om «vekk fra sengen, jeg sjokker», og at vedkommende konstaterer at ingen er i kontakt med sengen i det sjokket blir gitt.

Målet på kvalitet ble vurdert ut fra de nasjonale retningslinjene fra 2005 der brystkompresjonene skal ha en dybde på fire-fem centimeter og en frekvens på 100 per minutt. Dette skal gjennomføres med syklus på 30:2. Det vil si 30 brystkompresjoner etterfulgt av to innblåsninger/ventilasjoner (4). Når pasienten er intubert skal det utføres kontinuerlige brystkompresjoner og ventileres med en frekvens på ti per minutt. En internasjonal arbeidsgruppe har kommet med konsensus i forhold til mål på kvalitet. De skriver at to ventilasjoner bør kunne utføres på fem sekunder, rytmeanalyse på fem sekunder og et sjokk på tre sekunder. Dette gir en forventet hands-off tid på 
25 prosent ved bruk av 30:2 og 7 prosent når det utføres kontinuerlige brystkompresjoner på en intubert pasient. For å korte ned på hands-off tiden anbefaler de å komprimere mens defibrillatoren lades (9).

Ved hjertestans i avdelingen vil anestesilege bli kontaktet så fort som mulig, og en intubering vil skje innen relativt kort tid. I dette prosjektet deltok ikke anestesilege, og av den grunn ble det fokus på HLR med maske-bagventilasjon i scenario 1 og 2 . I det siste scenarioet var pasienten intubert på forhånd.

Alle deltakerne leverte inn evalueringsskjema på slutten av dagen som ble besvart anonymt. Skjemaet var ikke utarbeidet spesielt for dette prosjektet, men har blitt brukt som standard evalueringsskjema på SIM-senteret siden 2009. Alle spørsmål var lukkete og de fleste var gradert på en Likert-skala fra 1-5, der 5 tilsvarte «i svært stor grad» eller «svært enig». Kun ett spørsmål var gradert fra $1-10$, der 10 var best. I tillegg var noen svaralternativer «ja» og «nei».

Prosjektet ble i forkant godkjent av personvernombudet på OUS. De anbefalte ikke å innhente informert samtykke, da dette var obligatorisk trening. Etter deres råd ble det utlevert skriftlig informasjon til deltakerne vedrørende prosjektet og bruk av videofilene. Det ble tydelig presisert at videofilene ville bli slettet så fort data var registrert.

\section{RESULTATER}

De tre ulike scenarioene ble gjennomført åtte ganger, noe som gir totalt 24 scenarioer. Det ble registrert betydelige artefakter i forbindelse med håndventilering på trachealtube i scenario 3 , derfor er kompresjonsdata og hands-off tid kun fra de to første

TABELL 1: (data fra dukke og video)

Funn

\begin{tabular}{|c|c|c|}
\hline \multicolumn{3}{|c|}{ Kompresjoner $(n=8996)^{1}$} \\
\hline- & adekvat dybde, antall (\%) & 8250 (92) \\
\hline- & ikke sluppet helt opp [«leaning»], antall (\%) & $1136(13)$ \\
\hline- & trykke ned/slippe opp - forhold, mean (95\% Cl) & $0,98(0,97-0,99)$ \\
\hline- & dybde, mm, mean $(95 \% \mathrm{CI})$ & $48(44-52)$ \\
\hline- & kompresjonsfrekvens, mean (95\% CI) & $104(101-107)$ \\
\hline
\end{tabular}

Tid fra ventrikkelflimmer til første defibrillering, sek

scenario $1^{2}$, median (25-75\% kvartil)

$82(69-95)$

scenario $2^{3}$, median (25-75\% kvartil)

$25(20-41)$

scenario $3^{4}$, median (25-75\% kvartil)

$25(18-46)$

Tid fra ventrikkelflimmer til første komprimering, sek $^{5}$

alle scenarioer, median (25-75\% kvartil)

$11(7-21)$

Tid brukt på rytmesjekk, sek
1 min etter defibrillering, median (25-75\% kvartil)
$5(4-5)$
rytmesjekk + defibrillering, median (25-75\% kvartil)
$6(5-7)$
Tid fra levert sjokk til komprimering.
sek, median (25-75\% kvartil)
$4(3-5)$

Total varighet av pulsløs rytme ( $n=6409$ sek)

total registrert hands-off tid, sek $\left(\mathrm{HOF}^{6}\right)$

$1609(0,25)$

Hands-off fraksjon (HOF), mean (95\% CI)

$0,25(0,23-0,27)$

\footnotetext{
Ventilering på tube førte til mange artefakter i registreringen, derfor er data fra scenario 3 utelatt.

2 LP20 defibrillator står utenfor pasientrommet.

${ }^{3}$ LP20 defibrillator står inne på rommet.

${ }^{4}$ LP20 defibrillator står utenfor pasientrommet i 3 av 8 tilfeller.

${ }^{5}$ Beregnet ved start av scenarioet.

${ }^{6} \mathrm{HOF}=$ Hands - off fraksjon $=$ hands - off tid $/$ varighet av pulsløs rytme.
}

scenarioene (totalt 16). Det var også unormalt vanskelig å få tilstrekkelig luft i dukka ved maskebag-ventilasjon, og av den grunn er disse data ikke vurdert.

Kompresjonsfrekvens: Det ble registrert nesten 9000 brystkompresjoner og de hadde i gjennomsnitt en frekvens på 104, og en dybde på $48 \mathrm{~mm}$. Dybden var adekvat i 92 prosent av brystkompresjonene. Hver åttende brystkompresjon (13 prosent) ble ikke sluppet helt opp («leaning») (tabell 1).

Tid til «reaksjon»: Som tidligere nevnt er en av suksessfaktorene for overlevelse tidlig igangsetting av HLR og tidlig defibrillering. Under treningen tok det 11 sekunder (median) fra ventrikkelflimmer oppsto til komprimering ble påbegynt (tabell 1). Det gikk 82 sekunder (median) til første sjokk ble gitt i det første scenarioet, mens det 
gikk 25 sekunder (median) til sjokket ble avgitt i scenario to og tre (tabell 1).

Hands-off: Et annet godt mål for kvaliteten på AHLR er hands-off tid. I kliniske studier blir betegnelsen "no-flow» ofte benyttet da den tydeligere beskriver tiden uten sirkulasjon Den totale hands-off tiden var på 0,25 (25 prosent) (tabell 1). Videre ble rytmeanalyse og sjokk gitt på seks sekunder (median) og det gikk fire sekunder (median) fra levert sjokk til komprimering ble påbegynt (tabell 1).

Medikamenter: Adrenalin og Cordarone ble gitt korrekt i 92 prosent av tilfellene, og det var kun tre av 48 doser som ikke ble dobbeltkontrollert (tabell 2). Ved to tilfeller var det tendens til utydelig eller uklar leder i rommet (tabell 2). Ved det ene tilfellet førte dette til uklarhet i forhold til sløyfen, med den konsekvens at sjokk ble gitt på feil tidspunkt i sløyfen, og ved det andre tilfellet ble det ikke gitt medikamenter.

Kommunikasjon: Ved 40 av de 48 (83 prosent) medikamentdosene var det en tilfredsstillende kommunikasjon mellom den som ga medikamentet og den eller de som forordnet det («Closed loop»). Ved åtte tilfeller ble det gitt i «stillhet» (tabell 2).

Sikkerhet: Ved 67 av 81 (83 prosent) defibrilleringer ble dette utført korrekt etter tidligere nevnte sikkerhetskriterier. Ved alle tilfellene ble det opplyst tydelig verbalt at det skulle støtes, men ved 14 tilfeller så vedkommende på defibrillatoren og ikke sengen når sjokket ble utløst (tabell 2).

Påfølgende sjokk: Når defibrillatoren står i umiddelbar nærhet kan man ifølge de nasjonale retningslinjene gi to påfølgende støt ved ventrikkelflimmer (6). I dette prosjektet ble det gitt to påfølgende støt ved sju av 13 (54 prosent) tilfeller når defibrillatoren befant seg på rommet, og ved tre av 11 (38 prosent) tilfeller når defibrillatoren befant seg utenfor rommet (tabell 2). Det ble ved flere scenarioer diskutert om det skulle gis to støt eller ikke, og det virket som om det var noe usikkerhet rundt når dette kunne gjøres.
TABELL 2: (data observert fra video)

Funn

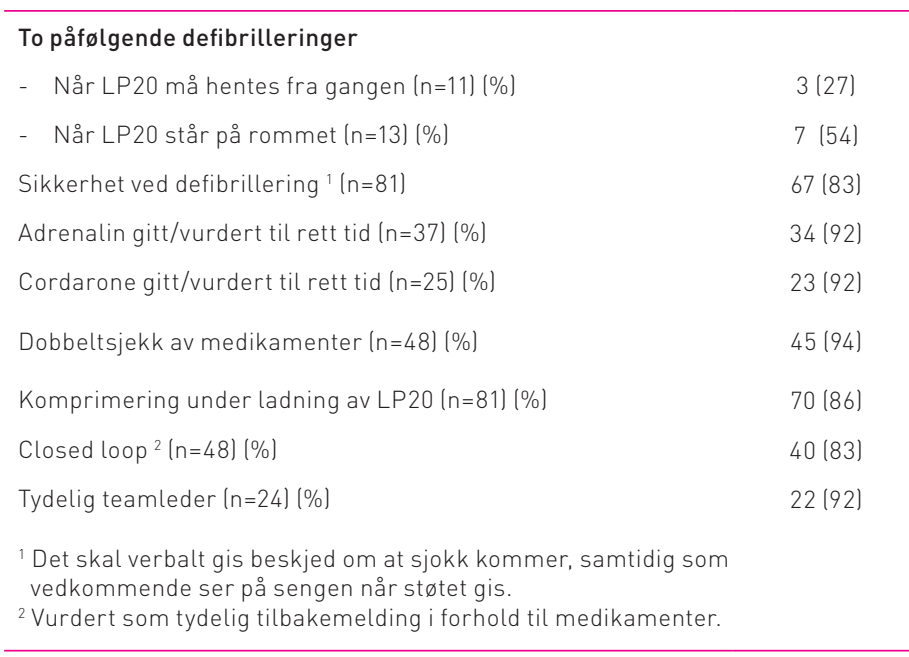

Komprimering under ladning: Ved 70 av 81 (86 prosent) tilfeller ble det komprimert mens defibrillatoren ble ladet (tabell 2). De fleste tilfellene der dette ikke ble fulgt var når det skulle sjokkes to ganger etter hverandre.

Evaluering: Det ble samlet inn totalt 52 besvarelser. På spørsmålet om hvor nyttig deltakeren synes treningen var, ble gjennomsnittskarakteren 9,33. Litt over halvparten (61 prosent) hadde gjennomgått AHLR-testen i forkant av treningen, mens det var mer beskjeden gjennomgang av e-læringsprogrammene (12-29 prosent). På spørsmål om hvor stor grad kursene bidro til at deltakeren var forberedt ble gjennomsnittskarakteren 3,63. De fleste mente at treningen i stor grad bidrar til økt trygghet i vanskelige situasjoner $(4,46)$ (tabell 3).

\section{DISKUSJON}

I de nasjonale retningslinjene fra 2005 anbefales en brystkompresjonsfrekvens på 100/min, og det er dette deltakerne tilstreber under trening. Studier på dyr har vist at en frekvens mellom 90-120 kan være akseptabelt (9), og en klinisk studie har vist at når kompresjonsfrekvensen faller under 90 så reduseres overlevelsen (10). Brystkompresjonene i dette prosjektet ligger tett opp til anbefalt frekvens, og hvis man legger til et vindu på 90-120 så er det god margin på begge sider. Nesten alle brystkompresjonene hadde tilfredsstillende dybde, med et gjennomsnitt på $48 \mathrm{~mm}$. Nedre grense ligger på $40 \mathrm{~mm}$, og 8 prosent lå under dette. For å bedre dette ved fremtidig trening så kan det drilles mer på hyppigere bytte av den som komprimerer, men også at teamet til en hver tid observerer at det blir utført tilfredsstillende brystkompresjoner. 
Det var en tendens til «leaning» på enkelte brystkompresjoner. I forbindelse med AHLR-trening er det lett å observere dette, og tilbakemeldinger kan gis direkte under pågående komprimering. Dette kan det fokuseres på videre. Det er uvisst hvor stor klinisk betydning det har at brystkompresjonene ikke blir sluppet helt opp, men det kan redusere hjertets fylning. Som mål på god HLR foreslår man det likevel som et valgfritt parameter (9).

Under treningen tok det 11 sekunder (median) fra ventrikkelflimmer oppsto til brystkompresjoner ble påbegynt (tabell 1). Denne tiden vil kunne være noe kortere ved en reell pasient. De kliniske observasjonene er ikke tilgjengelig ved trening på dukke, slik at scoopet blir eneste kilde for endring i tilstanden. Det kommer riktignok et lite stønn fra dukka i det ventrikkelflimmer oppstår, men dette ble ikke oppfattet av alle. Den samme feilkilden er gjeldende når det angår tid fra ventrikkelflimmer til første defibrillering, men har ikke prosentvis så stor betydning, da totaltiden er betydelig lenger. Det gikk 82 sekunder (median) til første sjokk ble gitt i det første scenarioet (tabell 1). Her var en sykepleier alene på stua med pasienten. I det ventrikkelflimmeret ble oppdaget måtte sykepleieren varsle og hente hjelp, samt få tak i defibrillatoren som sto på gangen. I de to andre scenarioene var det flere personer til stede når flimmeren oppsto, samt at defibrillatoren sto inne på rommet i de fleste tilfellene. Her gikk det 25 sekunder (median) til sjokket ble avgitt (tabell 1).

Hands-off tiden lå i gjennomsnitt på 0,25 (25 prosent). Dette er i henhold til den internasjonale arbeidsgruppa sine kvalitetsmål ved maske-bag-ventilasjon (9). Det er med andre ord ingen

TABELL 3: (evalueringsskjema)

Hvor nyttig mener du at dagens trening var for deg?

(skala fra 1-10, hvor 10 er best), mean

Gjennomført e-læringsprogram/AHLR-test i forkant av simuleringsdagen

Crisis resource management (CRM), \%

Medisinsk simulering, \%

LP20, \%

AHLR-test (www.nrr.org), \%

29

12

61

I hvilken grad bidro kurset/kursene til at du var tilstrekkelig forberedt til den praktiske treningen?

(Likert skala 1-5, hvor 5 er i svært stor grad), mean

Simuleringstrening gjør meg tryggere og bidrar til at jeg hand-

ler raskt og sikkert i vanskelige situasjoner

(Likert skala 1-5, hvor 5 er i svært stor grad), mean

Simuleringstrening har en sterk positiv virkning på arbeidsmiljøet i avdelingen

(Likert skala 1-5, hvor 5 er i svært stor grad), mean

At sykehuset tilbyr simuleringstrening opplever jeg som et tegn på at jeg blir ivaretatt som medarbeider

(Likert skala 1-5, hvor 5 er i svært stor grad), mean

Jeg opplever at diskusjonene under treningen virker

inspirerende og gjør meg mer motivert for jobben min

(Likert skala 1-5, hvor 5 er i svært stor grad), mean

Jeg er godt fornøyd med det læringsutbyttet jeg fikk gjennom debrifingene

(Likert skala 1-5, hvor 5 er i svært stor grad), mean

Jeg følte meg godt ivaretatt som kursdeltaker

(Likert skala 1-5, hvor 5 er i svært stor grad), mean

hands-off tid som brukes på annet enn ventilasjoner, sjokk og analyse. En klinisk studie fra Østerrike rapporterte om gode resultater i AHLR blant godt trent personell i en akuttavdeling. De kunne vise til en hands-off tid på 12,7 prosent. Her var pasientene intubert, og tilsvarende kvalitetsmål vil her ligge på 7 prosent. De målte også no-flow tiden i forbindelse med defibrillering. Den ble registrert til å være 11 sekunder (median) før sjokk og seks sekunder (median) etter levert sjokk (11). Data i dette prosjektet lå på henholdsvis seks og fire sekunder.

Sikkerheten ved defibrillering var tilfredsstillende, men at det ved 14 tilfeller ikke ble sett på senga når støtet ble gitt kan potensielt være en fare. Dette må det drilles mer på. Det er også et forbedringspotensial ved å komprimere under ladning, men det lille avviket (14 prosent) ga ingen store utslag på hands-off tiden.

Den største usikkerheten blant deltakerne var om det skulle sjokkes to ganger. De fleste avsto fra dette når defibrillatoren var plassert på gangen. Dette var korrekt ut fra avdelingens rutiner. Når den var på rommet derimot var det aktuelt å gi to støt, allikevel ble det utført i bare halvparten av tilfellene. Dette kan tydeliggjøres bedre til videre trening.

Lederskap og kommunikasjon var faktorer som ble observert gjennom videofilmene. En studie fra Sveits (2003) viste at fravær av 
lederskap og fordeling av oppgaver førte til nedsatt teamprestasjon (12). Det var ved to tilfeller tendens til uklar eller utydelig leder i rommet. Dette førte til at de kom litt ut av sløyfen. Totalt sett fikk dette liten betydning for resultatene, men isolert sett er det viktig å se at dårlig kommunikasjon og ledelse kan føre til dårligere utførelse av HLR. Slike data vil selvfølgelig være noe usikre da de baserer seg på prosjektleders subjektive vurderinger.

Evalueringsskjemaene viste generelt en stor tilfredshet ved simuleringstrening. Trening skaper trygghet og deltakerne føler seg ivaretatt. Det eneste deltakerne var noe usikre på var om e-læringskursene og AHLR-testen bidro til at de var bedre forberedt. Slike programmer brukes fordi det antas å ha en nytteverdi forut for praktiske tester, men et nylig utgitt randomisert studie fra England viser at dette ikke hadde noen effekt på prestasjonene ved AHLR simuleringstrening (13). Viktigheten av slike forberedende kurs kan derfor diskuteres.

Resultater fra simuleringstre-

\section{REFERANSELISTE}

1. Norsk Resuscitasjonsråd (NRR) (www. nrr.org). Tilgjengelig 8. juni 2011 fra: http://www.nrr.org/?page_id=1285

2. Handley AJ, Koster R, Monsieurs K, Perkins GD, Davies S, Bossaert L, et al. European Resuscitation Council guidelines for resuscitation 2005. Section 2. Adult basic life support and use of automated external defibrillators. (Erratum appears in Resuscitation. 2006;69:351). Resuscitation 2005;67: Suppl 23.

3. Wik L, Kramer-Johansen J, Myklebust $H$, Sorebo H, Svensson L, Fellows B, et al. Quality of cardiopulmonary resuscitation during out-of-hospital cardiac arrest. JAMA 2005;293:299-304.

4. Abella BS, Alvarado JP, Myklebust $H$, Edelson DP, Barry A, O>Hearn N, et al. Quality of cardiopulmonary resuscitation during in-hospital cardiac arrest. JAMA 2005;293:305-10.

5. Retningslinjer for Basal HLR (BHLR) Voksne. Norsk Resuscitasjonsråd (NRR) 2005 (www.nrr.org). Tilgjengelig 8. juni ning vil selvfølgelig aldri kunne sammenliknes 100 prosent med praksis. Til det er situasjonene for kunstig. Allikevel er det teknisk mulig å få det relativt autentisk. Uansett er deltakerne forberedt på at noe vil skje og dette kan bedre responstiden og gi falskt positivt resultat. På den andre siden jobber deltakerne med denne pasientgruppen til daglig og er vant med at hjertestans skjer fra tid til annen. På en hjerteovervåkning er det alltid en person som sitter vakt ved scoopsentralen og som vil oppdage hjertestans umiddelbart.

Det vil også være visse svakheter knyttet til data som er registrert fra dukke til PC. Kompresjonsfrekvens og kompresjonsdybde avleses som gjennomsnittsmålinger etter endt scenario. Teoretisk kan det med andre ord bli komprimert for fort eller dypt i starten av et scenario og for sakte eller grunt på slutten, men likevel ende opp med et tilfredsstillende gjennomsnitt. Hva gjelder kompresjonsdybde så må det genereres et trykk på 30 kilo for å trykke ned brystkassen til

2011 fra: http://www.nrr.org/wp-content/ uploads/pdf/guidelines/norske_2005/2_ BHLR_retningslinjer_2005.pdf

6.Retningslinjer for Avansert hjertelunge-redning (AHLR) - voksne. Norsk Resuscitasjonsråd (NRR) 2005 (www.nrr. org). Tilgjengelig 8. juni 2011 fra: http:// www.nrr.org/wp-content/uploads/pdf/ guidelines/norske_2005/5_AHLR_retningslinjer_2005.pdf

7. Olasveengen TM, Vik E, Kuzovlev A, Sunde K. Effect of implementation of new resuscitation guidelines on quality of cardiopulmonary resuscitation and survival. Resuscitation 2009;80:407-11.

8. Mangschau A. Årsrapport 2009, Kardiologisk intensiv og overvåkning. Internt dokument, OUS, Ullevål 2010

9. Kramer-Johansen J, Edelson DP, Losert H, Kohler K, Abella BS. Uniform reporting of measured quality of cardiopulmonary resuscitation (CPR). Resuscitation 2007;74:406-17.

10. Abella BS, Sandbo N, Vassilatos P, Alvarado JP, O>Hearn N, Wigder HN, dukka fire centimeter. I praksis vil selvfølgelig nødvendig kraft variere fra pasient til pasient avhengig av størrelse, vekt og stivhet i brystkassen. I så måte vil ikke tilfredsstillende kompresjonsdybde på dukka nødvendigvis si noe om hvor godt man vil komprimere ved en reell hjertestans.

\section{KONKLUSJON}

Kvaliteten på utført AHLR ved simulatortrening tilfredsstiller de nasjonale retningslinjene fra 2005. Algoritmen blir fulgt i så godt som alle scenarioer, og den tekniske utførelsen er god. Hands-off tiden var på 25 prosent, noe som er forventet ved maske-bag-ventilasjon. Resultatene tilsier derfor ingen unødig hands-off tid. Forbedringspotensialene ligger i økt fokus på sikkerhet ved DC-støt, samt å gi påfølgende DC-støt når defibrillatoren er i umiddelbar nærhet. En stor takk til avdelingsleder Ann-Hege Kofoed som ser viktigheten av kompetanseheving og fagutvikling, og derfor prioriterer blant annet AHLR-trening to ganger $i$ året.

et al. Chest compression rates during cardiopulmonary resuscitation are suboptimal: a prospective study during in-hospital cardiac arrest. Circulation 2005;111:428-34

11. Losert H, Sterz F, Kohler K, Sodeck $G$, Fleischhackl R, Eisenburger $P$, et al. Quality of cardiopulmonary resuscitation among highly trained staff in an emergency department setting. Arch Intern Med 2006;166:2375-80.

12. Marsch SCU, Muller C, Marquardt K, Conrad G, Tschan F, Hunziker PR. Human factors affect the quality of cardiopulmonary resuscitation in simulated cardiac arrests. Resuscitation 2004;60:51-56.

13. Perkins GD, Fullerton JN, DavisGomez N, Davies RP, Baldock C, Stevens $\mathrm{H}$, et al. The effect of pre-course e-learning prior to advanced life support training: a randomised controlled trial. Resuscitation 2010;81:877-81.

Les kommentaren på side 347 》 